Insisiva Dental Journal, Vol. 6 No.1 Bulan Mei Tahun 2017

\title{
Perawatan Saluran Akar pada Gigi Incisivus Sentral dan Lateral Maksila dengan Perbedaan Status Pulpa: Laporan
}

\section{Kasus}

\author{
Endodontic Treatment of Maxillary Central and Lateral Inci- \\ sor with Different Pulp Status: A Case Report
}

\author{
Yusrini Pasril \\ Yogyakarta \\ Korespondensi: yusrinipasril@yahoo.com
}

Clinical Department of Conservative Dentistry Universitas Muhammadiyah

\begin{abstract}
Abstrak
Perawatan Saluran Akar (PSA) merupakan terapi yang tepat untuk mempertahankan gigi pada perawatan gigi di era modern. Seperti yang diketahui, perawatan saluran akar merupakan perawatan yang membutuhkan aspek khusus dan kemampuan teknis dalam merestorasi gigi akibat trauma atau komplikasi dari karies gigi. Patologi karies gigi menunjukkan secara lambat laun kematian pulpa dan munculnya abses periapical. Hal ini lah yang membedakan prosedur perawatan dan keberhasilannya dari kebutuhan perawatan saluran akar. Oleh karena itu, penegakkan status pulpa penting untuk diketahui sebelum melakukan perawatan saluran akar.
\end{abstract}

Kata Kunci: perawatan saluran akar, status pulpa, incisivus maksila

\begin{abstract}
Endodontic treatment is an efficacious therapeutic as tooth preservation in the era of modern dental care. As known that endodontic treatment is one of the most specialized treatment aspect and demanding high technical skills in restorative dentistry due to injury or complication of untreated dental caries. The pathology of dental caries present slow by the death of the pulp and periapical abscess. This may give differences between the procedure of endodontic treatment's needs and prognoses. The pulp status of the tooth must be concerned before considering the endodontic treatment.
\end{abstract}

\section{PENDAHULUAN}

Karies gigi merupakan penyakit yang umumnya melibatkan komponen bakteri dan kebiasaan seseorang ${ }^{1}$. Karies gigi atau "tooth decay" disebut juga sebagai penyakit mikrobiologi yang mempengaruhi secara lokal di rongga mulut dan secara sistemik pada kasus ekstrim. Patobiologi karies gigi dihasilkan dari terlarutnya struktur mineral gigi, dari tiga komponen dasar yang ditemukan saat manifestasi klinis karies, diantaranya struktur gigi, bakteri asidogenik, karbohidrat yang terfermentasi untuk dimetabolisme oleh bakteri ${ }^{2}$. Pulpa gigi merupakan jaringan ikat yang mengandung saraf, pembuluh darah, substansi dasar, cairan intertisial, odontoblast, fibroblast, dan komponen selular lainnya. Secara historis, terdapat berbagai macam klasifikasi sistem diagnostik untuk menegakkan penyakit endodontik ${ }^{3}$. Klinisi harus mendengarkan gejala 
Yusrini Pasril | Perawatan Saluran Akar pada Gigi Incisivus Sentral dan Lateral Maksila dengan Perbedaan Status Pulpa: Laporan Kasus

penyakit dari pasien dan mengumpulkan temuan klinis dari hasil tes untuk membuat keputusan, seperti nyeri yang dirasakan dan kesehatan pulpa dari gigi yang menjadi suspek. Jika dua atau lebih tes menunjukkan sebuah gigi nonvital dan terdapat bukti perubahan radiologi lalu klinisi dapat meyakini temuan diagnosa. Jika masih belum yakin dengan suatu diagnosa, atau temuan klinis tidak menunjukkan dalam waktu observasi, maka akan lebih baik dilakukan rujukan ${ }^{4}$. Perawatan saluran akar dilakukan pada kondisi gigi dengan patologis pulpa atau periapikal. Selain itu, terdapat kondisi yang menjadi pilihan untuk dilakukan perawatan saluran akar, diantaranya pada gigi yang telah dilakukan pemasangan mahkota jaket dan butuh dilakukan pasak, gigi dengan overdenture, dan gigi dengan vitalitas pulpa yang meragukan ${ }^{5}$.

\section{LAPORAN KASUS}

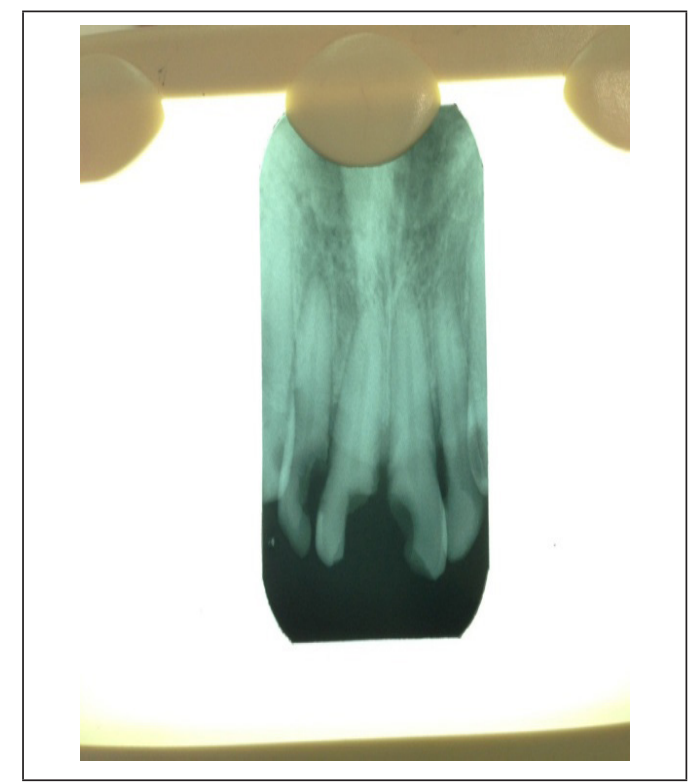

Gambar.1 Preoperatif radiograf

Seorang pasien perempuan usia 44 tahun, datang mengeluhkan giginya yang berlubang besar dan terlihat kehitaman pada bagian depan atasnya. Pasien merasakan giginya mulai berlubang sejak SMP dan sedikit demi sedikit lepas hingga menjadi lubang besar seperti sekarang. Pasien merasa kurang nyaman dan mengganggu penampilannya. Setahun yang lalu pasien pernah merasakan sedikit ngilu saat terkena angin dalam durasi yang lama namun sekarang ini pasien tidak merasakan adanya keluhan rasa sakit. Pasien mengaku bahwa gigi tersebut belum pernah dilakukan perawatan apapun dan tidak dicurigai memiliki riwayat penyakit sistemik. Pemeriksaan intraoral, pasien memiliki oklusi yang abnormal, Maloklusi Angle Kelas III tipe dentoskeletal disertai crossbite pada gigi anterior dan ditemukan adanya kavitas pada gigi 21 bagian mesial yang meluas hingga incisal dan palatal dengan kedalaman dentin. Sondasi (-), perkusi (+), palpasi (-), CE (-, dingin). Diagnosa awal sebelum dilakukan pemeriksaan penunjang menunjukkan nerkrosis pulpa. Setelah dilakukan pembersihan kavitas dari jaringan karies dengan bur bulat, pasien merasakan adanya tes kavitas $(+)$ dan $\mathrm{CE}(+)$, linu sehinga penegakkan diagnosa kerja gigi 21 adalah pulpitis irreversible asimptomatik disertai periodontitis apikalis kronis. Selain itu, kavitas juga ditemukan pada gigi 21 yang mengalami karies pada bagian incisal hingga bagian mesial meluas melibatkan pulpa, sondasi (-), perkusi (-), palpasi (-), CE (-). Pada pemeriksaan penunjang gigi 11 mendukung diagnosa kerja, yaitu nekrosis pulpa.

\section{RENCANA PERAWATAN}

Tujuan perawatan ini untuk meningkatkan estetik pada gigi anterior rahang atas dan menghilangkan rasa linu paska dilakukan pembersihan karies pada gigi 21. Pulpektomi dilakukan pada gigi 21 di kunjungan pertama 
untuk mengurangi rasa linu dan sekaligus dilakukan open akses serta ekstirpasi jaringan pulpa. Preparasi biomekanik yang diikuti dengan medikasi pada saluran akar dilakukan pada kunjungan selanjutnya. Obturasi saluran akar dilakukan setelah saluran akar telah steril. Restorasi paska perawatan saluran akarn direncanakan menggunakan pasak fiber reinforce composite (FRC) dengan mahkota jaket resin komposit dengan pertimbangan abnormalitas oklusi pasien.

Perawatan Saluran Akar (PSA) gigi 11 dan 21

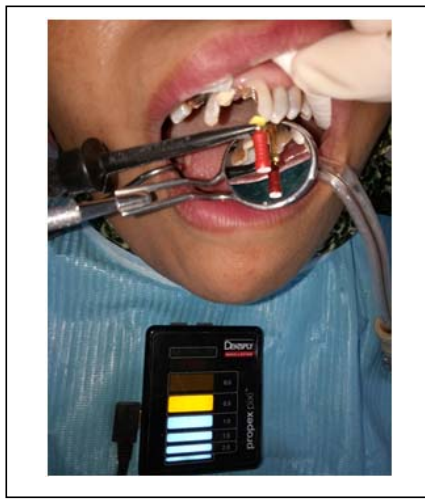

Gambar 2. Penentuan IAF menggunaan EAL

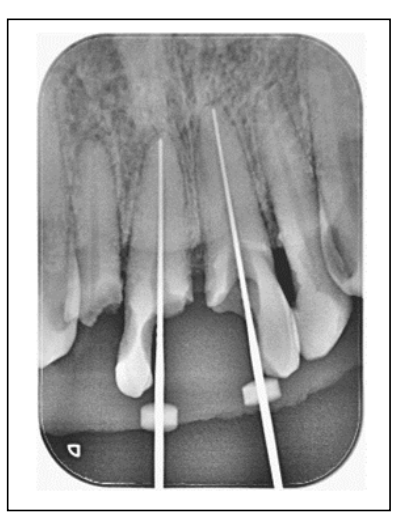

Gambar 3. Pengukuran menggunakan IAF

\section{MANAJEMEN KASUS}

Pulpektomi

Pasien dilakukan anestesi disekitar mukosa labia dan palatal pada gigi 21 menggunakan Lidokain $\mathrm{HCl}$ 2\% 1:100 (2 ml) yang dilanjutkan dengan pengambilan jaringan pulpa menggunakan jarum ekstirpasi. Irigasi kombinasi dilakukan dengan menggunakan salin dan $\mathrm{NaOCl}$ 2,5\%. Pemberian medikasi pada kamar pulpa menggunakan Cresophen dan direstorasi sementara dengan Caviton (GC Asia, Japan).

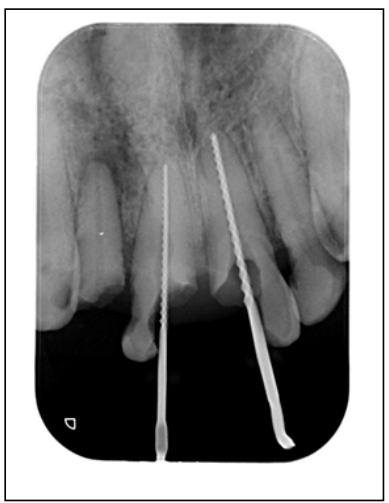

Gambar 4.

Pengukuran menggunakan MAF menggunakan MAC

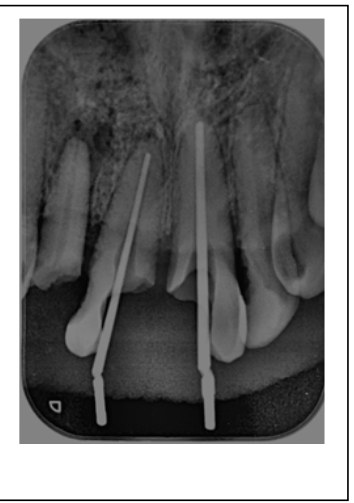

Gambar 5.

Pengukuran

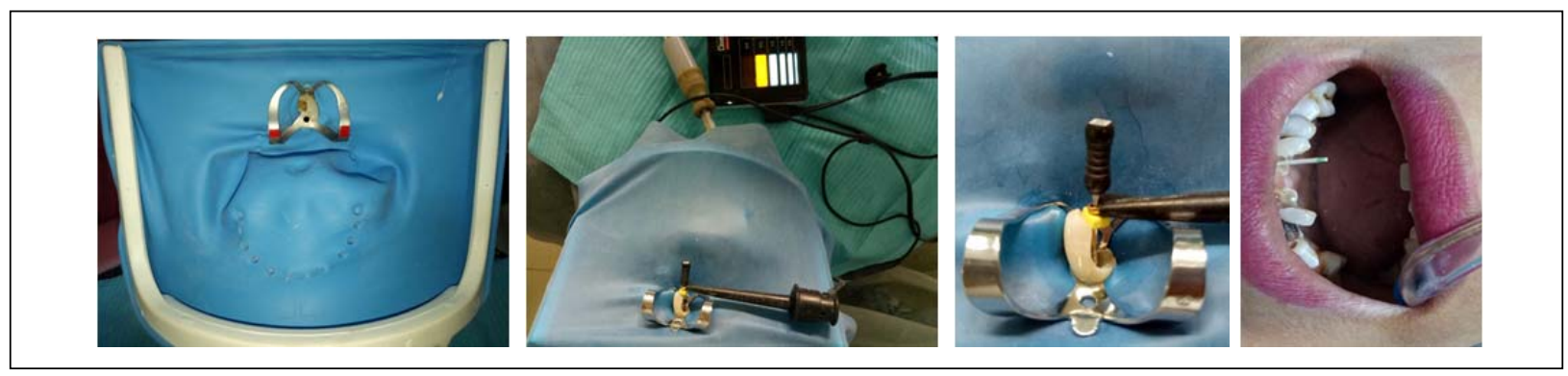

Gambar 6. Preparasi Biomekanik

Perawatan saluran akar dilakukan beberapa kali kunjungan. Pengukuran panjang kerja menggunakan electronic apex locator (EAL), Propex (Dentsply) dan dikonfirmasi menggunakan pengambilan radiograf periapikal untuk memperoleh initial apical file (IAF), hingga memperoleh sensasi tuck bag. Preparasi biomekanik dilakukan menggunakan teknik step back. Medikasi menggunakan Cresophen selama 3-7 hari dan menggunakan pasta $\mathrm{CaOH}$ 
Yusrini Pasril | Perawatan Saluran Akar pada Gigi Incisivus Sentral dan Lateral Maksila dengan Perbedaan Status Pulpa: Laporan Kasus

murni selama 1 minggu sebelum dilakukan obturasi. Tes bakteri dilakukan menggunakan papper point yang direndam Hidrogen Peroksida. Hasil tes bakteri akan menunjukkan negatif apabila tidak menunjukkan adanya gelembung, tidak berbau, dan tidak ada perubahan warna pada papper point. Obturasi dilakukan menggunakan gutta percha MAC dengan bahan sealer Endhometason yang dipotong di bawah servikal. Saluran akar yang telah dilakukan obturasi direstorasi semengtara menggunakan bahan SIK Fuji IX capsul (GC, Japan). Follow up dan evaluasi dilakukan setelah 1 bulan.

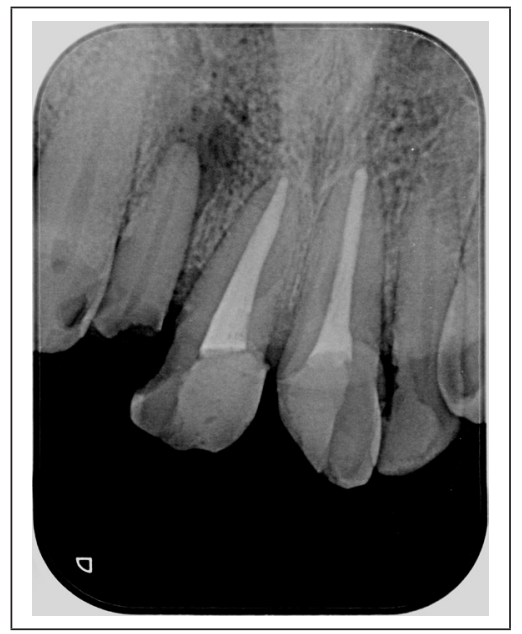

\section{Gambar 7. Follow Up setelah 1 bulan}

\section{Perawatan Saluran Akar (PSA) gigi 12}

Gigi 12 ditemukan kondisi kavitas karies kedalaman pulpa dengan sondasi (-), perkusi $(+)$, palpasi (+), CE (-). Penampakan klinis terdapat pembengkakan pada bagian palatal. Setelah dilakukan pemeriksaan penunjang, ditetapkan diagnosa kerja nekrosis pulpa disertai abses periapikal. Pada kunjungan ini dilakukan. pemberian medikasi antibiotik disertai pengambilan jaringan pulpa yang terinfeksi.

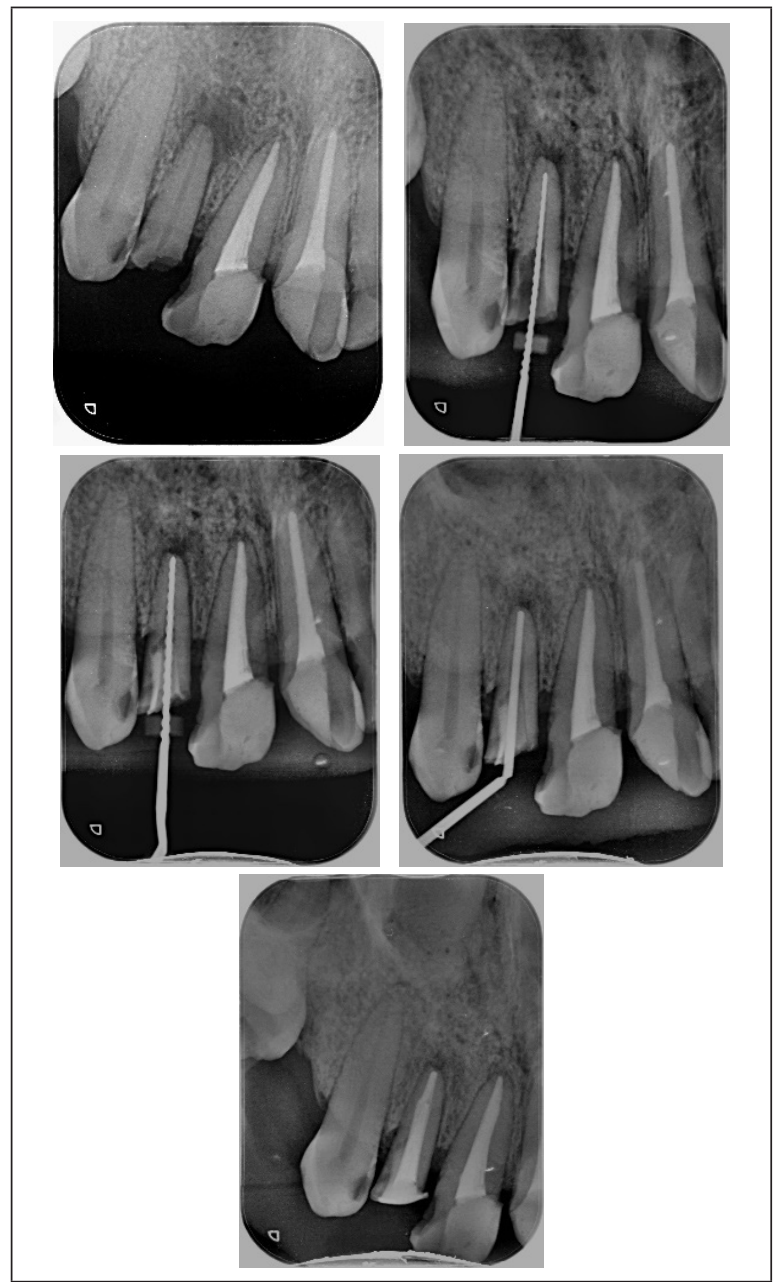

Gambar 8. Dilakukan PSA pada gigi 12

\section{DISKUSI}

Karies pada gigi anterior yang telah meluas membawa dampak pada kesehatan, fungsi gigi dan estetis ${ }^{6}$. Ketika karies mencapai pulpa, banyak pertimbangan untuk perawatan pada gigi tersebut karena struktur gigi telah rapuh ${ }^{7}$. Salah satu pilihan pada gigi dengan karies yang luas dengan melakukan ekstraksi lalu dilanjutkan dengan pembuatan protesa atau implan ${ }^{8}$. Namun, pembuatan protesa akan membutuhkan prinsip biologis, mekanis dan estetis yang sesuai. Selain itu, pada pemeriksaan klinis menunjukkan adanya lesi periapikal yang harus dihilangkan untuk meningkatkan fungsi gigi. Adanya perawatan saluran akar, maka diharapkan akan memperbaiki fungsi 
estetis dan meminimalisir kontaminasi lesi disekitar apikal. Penelitian menunjukkan bahwa instrumentasi dan irigasi pada perawatan saluran akar mengurangi jumlah mikroorganisme tetapi tidak menghilangkan seluruhnya, sehingga dibutuhkan dressing intrakanal dengan bahan rekomendasi yaitu Kalsium Hidroksida ${ }^{9}$. Adapun kegagalan perawatan saluran akar dapat diakibatkan rekontaminasi dari rongga mulut karena restorasi sementara yang tidak adekuat ${ }^{10}$. Oleh karena itu, dokter gigi sebaiknya membuat restorasi permanen yang efektif ketika perawatan saluran akar telah selesai untuk menghindari rekontaminasi bakteri. Selain itu, diperlukan bahan yang adekuat untuk mencegah kebocoran koronal paska perawatan saluran akar. Beberapa bahan yang umunya digunakan diantaranya, Glass Ionomer Cement (GIC), Resin Modified Glass Ionomer (RMGIC), Resin Komposit, reinforce GIC, amalgam, bahan restorasi sementara reinforced berbasis Zinc Oxide eugenol (mis. IRM Dentsply Caulk,Milford, USA), dan bahan restorasi berbasis Calcium Sulfat (mis. Cavit -3M ESPE, Seefeld, Germany) ${ }^{11}$. Penggunaan GIC Fuji IX capsul (GC Asia, Japan) sebagai restorasi sementara paska obturasi dilakukan pada kasus ini dengan pengurangan coronal seal $1 \mathrm{~mm}$ dibawah cementoenamel junction (CEJ) untuk memastikan gigi tersebut terhindar dari rekontaminasi. Setelahnya dilakukan follow up selama 1 bulan pertama serta dilakukan evaluasi klinis restorasi sementara tersebut terlihat masih baik, didukung dengan hasil pemeriksaan radiograf yang menunjukkan mengecilnya area radiolusen pada ujung apikal gigi 12 setelah perawatan saluran akar.

\section{KESIMPULAN}

Perawatan saluran akar pada gigi yang mengalami karies luas akan menimbulkan perbedaan status pulpa. Pertimbangan dalam menentukan rencana perawatan saluran akar bergantung dari diagnosa status pulpa yang ditemukan. Sehingga, perlu dilakukannya seleksi kasus untuk perawatan saluran akar sekaligus mempertimbangkan bahan restorasi estetik yang akan digunakan sebagai restorasi sementara tanpa menghiraukan oklusi dari gigi tersebut dan restorasi permanen setelahnya.

\section{DAFTAR PUSTAKA}

1. Quock, R. L. 2015. Dental Caries: A current understanding and implications. Journal of Nature and Science, I, 1-4.

2. Heymann, H., Swift, E., \& Ritter, A. 2013. Sturdevant's Art and Science of Operative Dentistry 6th Ed. Chapel Hill, North Carolina: Mosby: St. Louis.

3. Glickman, G. 2009. Conference on Diagnostic Terminology: background and perspectives. Journal of Endodontic, 35.

4. Martin Dunitz Ltd. 2002. Endodontics Problem-Solving in Clinical Practice. United Kingdom: Taylor \& Francis group.

5. Carrotte, P. 2004. Endodontics: Part 2 Diagnosis and Treatment Planning. British Dental Journal, 235.

6. Correia AMO, V. V. 2005. Aesthetic Restoration of Maxillary Incisors with Composites: Case Report. Austin Journal Dent, II (1), 1-3. (Online), (www. austinpublishinggroup.com)

7. McComb, D. (2008, February/March). Restoration of the Endodontically Treated Tooth. Ensuring Continued Trust, p. 23. 
Yusrini Pasril | Perawatan Saluran Akar pada Gigi Incisivus Sentral dan Lateral Maksila dengan Perbedaan Status Pulpa: Laporan Kasus

8. Savi A, M. M. 2008. Use of customized fiber posts for the aesthetic treatment of severely compromised teeth: a case report. Dental Traumatology, 671-675.

9. Sornkul, E. a. 1992. Strength of roots before and after endodontic treatment and restoration. Journal of Endodontics, 440443.
10. Khan, M., Khan, R., Javed, M., Ahmed, A., \& Nabeel, M. 2011. Treatment of Acute Apical Abscess by Single Visit Endodontics - 2 case reports. Pakistan Oral \& Dental Journal, 199-201.

11. Sturdevant C, R. T. 2011. Sturdevant J. The Art and Science of Operative Dentistry. North California: Elsevier. 